\title{
El misionero James Barker: ¿El pánini de la lengua yanomami?
}

\author{
Missionary James Barker. The Pánini of \\ the Yanomami language?
}

Esteban Emilio Mosonyi ${ }^{1}$

\section{Resumen}

El artículo titulado "Una gramática técnica de la lengua shamatari" constituye un trabajo poco conocido y menos aun aprovechado por los buenos lingüistas contemporáneos que han trabajado con el idioma yanomami -el shamatari vendría siendo su variante centralpor tratarse de un estudio casi clandestino: publicado en el Boletín Indigenista Venezolano (XVIII (Enero-Junio de 1979), 15, Caracas). Yo mismo lo subestimé un poco al inicio, por razones más bien formales: mal uso del castellano, una concisión algo críptica, entre otras características atípicas. Sin embargo, más adelante tuve que admitir que en el fondo es una descripción sumamente densa y precisa de varias categorías de la morfosintaxis fundamental de la lengua, lo que en cierto modo me hizo recordar al gran proto-lingüista hindú Pánini.

\begin{abstract}
The article entitled "Una gramática técnica de la lengua Shamatari" (A technical grammar of the Shamatari language) is a scarcely known work, even less utilized by good contemporary linguists dedicated to the study of Yanomami - Shamatari being its central variety - as it ventured to be an almost clandestine study, published in the Boletín Indigenista Venezolano (XVIII (January-June, 1979), 15, Caracas). Even I undervalued it initially to a certain degree, because of a couple of rather formal reasons: deficient use of the Spanish language, its somewhat criptical concision, among other atypical characteristics. Later on I had to admit, however, that it constitutes fundamentally a very compact and precise description of several basic morphosyntactic categories of this language, which in fact reminded me of the eminent Indian proto-linguist Panini.
\end{abstract}

\section{Yai pata ãwã yanomami-prariyoma}

1. Mashita a pata kuo mao tëhë, pei kë ãwã kuo parioma. Yai pata thë sho ĩhَ̃ ãwã kuoma. Pei ãwã Yai pata thë kuoma.

2. Hapa totihiwë, Yai pata thë kuoma, îhì ãwã sho.

\footnotetext{
${ }^{1}$ Profesor Titular de Antropología y Lingüística de la Universidad Central de Venezuela; Rector de la Universidad Nacional Experimental Indígena de Tauca, Estado BolívarVenezuela.
} 
La palabra de Dios hecha hombre

1. Cuando todo comenzó, ya existía la Palabra; y aquel que es la Palabra estaba con Dios y era Dios.

En el principio, pues, él estaba con Dios.

Evangelio de San Juan

\section{I.}

Eran todavía los años finales de la década de los setenta, en pleno siglo pasado, aunque ya se asomaban los destellos de un nuevo milenio que se aproximaba lentamente. La lucha por los derechos de los pueblos indígenas estaba en su apogeo, incluso se habían ganado las primeras batallas. En algunos sectores académicos de los países más diversos se apreciaba cierto entusiasmo por investigar más a fondo las sociedades y culturas aborígenes, incluidos sus idiomas. Ese interés no era por supuesto de carácter estrictamente académico. Se asomaban como siempre otras motivaciones, entre ellas el impulso -por no decir compulsión- de evangelizar a estos pueblos, especialmente por parte de algunos agrupamientos protestantes; por ejemplo, las "Misiones Nuevas Tribus", estrechamente vinculadas aunque no identificables con el conocidísimo Instituto Lingüístico de Verano (Summer Institute of Linguistics), a quien le debemos - hay que admitirlo por encima de las muy merecidas críticas - la descripción sistemática, parcial o profunda de centenares de lenguas indígenas a través del mundo (Makkai 1984).

La formación lingüística de esos misioneros, llamados corrientemente "evangélicos", era y todavía sigue siendo muy desigual, así como su interés por la lengua local podía no ser muy genuino. Pero en todos sus trabajos, incluso los más elementales, se percibe con mucha claridad el estructuralismo tagmémico del Instituto Lingüístico de Verano. Este, en su momento, constituía una escuela teórico-métodológica muy importante, de estirpe evidentemente norteamericana, especialmente antes del "triunfo" -que más adelante probó ser ilusorio a largo plazo- de la escuela generativa, previamente más conocida como transformacional. Esta floreció, no obstante, durante largo tiempo bajo la égida del maestro Noam Chomsky, hoy día quizás más dedicado al análisis político anti-imperialista.

Si bien el objetivo fundamental de los misioneros -aparte de evangelizar y occidentalizar dentro de un esquema capitalista a estos pueblos minorizados, aunque cada vez más insurgentes- era la traducción de la Biblia, especialmente la del Nuevo Testamento, algunos de ellos llegaron a enamorarse de las lenguas con las que les tocó trabajar, hasta el punto de que no pocos llegaron a alcanzar una altura académica considerable, empezando por la figura imborrable de un 
Kenneth Pike (Pike 1954). El misionero norteamericano James Barker, miembro de las Nuevas Tribus destacado en el sur del Amazonas venezolano, fue sin duda uno de ellos. Lo conocí en plena actividad durante los primeros años de mi vida profesional; ya me cuesta recordar incluso la fecha exacta, de manera que solo conservo un recuerdo confuso de su persona. Era un señor alto, corpulento, de aspecto bonachón, barbudo y moderadamente pelirrojo, muy muy parecido a los numerosos granjeros de ascendencia "wasp" -palabra que significa "avispa" y se desglosa en "White Anglo-Saxon Protestant"- de presencia tan común en el medio-oeste estadounidense. Parecía una persona afable, incluso cariñosa, que actuaba sin duda de buena fe e impulsada por sus creencias religiosas. Solo tuvimos la ocasión de conversar muy pocas palabras. Su español era menos que rudimentario, tanto en lo fonológico como en su poca pericia morfosintáctica y menos aún pragmática. No obstante todo parecía indicar que su conocimiento -incluso coloquial- del yanomami local era mucho más avanzado.

De esto apenas podrá haber algún asomo de duda, cuando hagamos el balance del trabajo lingüístico que pronto pasaremos a comentar. Los colegas y la gente conocedora de esta problemática saben desde hace tiempo de mi animadversión frente a la evangelización sustitutiva de prácticamente todo lo que constituye el patrimonio intangible, y a veces tangible, de nuestras muy queridas y apreciadas culturas indígenas (Escobar 1988). Contra todo eso he sido un luchador incansable, particularmente cuando se trata de grupos fundamentalistas fanatizados: y las Nuevas Tribus bien merecen ese nombre. Mas también hay que reconocer que por razones de variada índole especialmente para lograr mayor acceso a la mente y a la manera de ser de los pueblos indígenas- ellos han privilegiado en cierto modo los idiomas indígenas, poniéndoles en general mayor cuidado que sus competidores católicos. Estos suelen carecer, en su gran mayoría, de toda pericia lingüística o, en algunos casos, recurren a sus conocimientos de gramática escolar latinizante, que ve y juzga a las lenguas indígenas desde la perspectiva del español en tanto lengua romance.

Esto es tan cierto que inclusive un investigador talentoso y dedicado como lo fue el Padre Fray Cesáreo de Armellada tuvo la convicción de que los dos fonemas centrales del idioma caribe pemón -me refiero al /a/ y al /it/- no eran más que desviaciones caprichosas a partir de las cinco vocales "normales" del latín clásico y del mismo español: a, e, i, o, u. Frente a errores tan gruesos y elementales, la actitud del misionero evangélico menos versado en lingüística es mucho más receptiva a la verdad de los hechos, aunque -también es bueno decirlo- ese mayor conocimiento no siempre es reflejado en los alfabetos diseñados por ellos y ni siquiera en sus textos bíblicos. Pero volviendo al caso que nos ocupa, el predicador James Barker, este hizo un esfuerzo muy meritorio por penetrar en los intrincados y nada sencillos secretos de la lengua yanomami $\mathrm{y}$ en transmitirnos esa experiencia de la mejor manera que estuvo a su alcance. 
Antes de pasar a mi objetivo central -el cual es dar a conocer su aporte, con sus aciertos y errores- querría todavía agregar algo a la semblanza de este misionero evangélico.

Sucede que mucho tiempo -en realidad largos años- después de nuestro brevísimo encuentro llegó a mis oídos un rumor no comprobado, pero creíble en virtud de sus fuentes, de que finalmente Barker se retiró de su misión de Mavaca, decepcionado por el obvio carácter destructivo del evangelismo ultrafundamentalista, a cuya difusión acrítica le dedicó los mejores años de su vida. Si eso fue así, vayan ahora mis mejores reconocimientos al señor Barker donde quiera que se encuentre ahora, también por su entereza como ser humano.

\section{II.}

Mi aproximación al ensayo gramatical de James Barker data del año 1978, aproximadamente un año antes de su publicación por el Boletín Indigenista Venezolano. Ya habían transcurrido varios años, no recuerdo cuántos, desde nuestra entrevista casi instantánea en el campo orinoquense. Un día cualquiera, el antropólogo y farmacéutico ecuatoriano-venezolano Luis Jeremías - hombre muy preparado y Director a la sazón de dicha revista - me llamó y puso en mis manos un manuscrito de extraño aspecto que resultó ser un trabajo titulado "Una gramática técnica de la lengua shamatari”, precisamente de nuestro amigo James Barker. Yo me quedé muy sorprendido cuando comencé a hojear el material. Y no era para menos. Se veía como un manojo de papeles viejos y desordenados, en parte casi ilegibles, plagados de errores detectables a simple vista, y para colmo escritos en un mal castellano. La verdad es que el aporte en cuestión no parecía prometer demasiado. El profesor Jeremías incluso sostenía el punto de vista de que ese material tan pobremente presentado no era digno de publicación, particularmente por motivo de que ya había lingüístas profesionales trabajando sobre el terreno. En ese momento yo tampoco estaba muy entusiasmado pero no quería pronunciarme demasiado a la ligera, dada la importancia del idioma y la poca cantidad de trabajos confiables y disponibles para la fecha. Quedamos en que yo iba a examinar atentamente el manuscrito para después tomar una decisión acertada. Pero en mi propia posición predominó con mucho un escepticismo casi total, que a mi entender todavía sigue prevaleciendo en los excelentes lingüistas y antropólogos profesionales que luego se ocuparon de este interesantísimo idioma, dándonos meritorias y además muy variadas contribuciones.

Al día siguiente comencé mi revisión del ensayo presentado. Mi primera impresión siguió siendo la de una confusión total; el escrito parecía reducirse a un galimatías incomprensible, semi-elaborado en el mejor de los casos. La mala calidad del español acrecentaba mi actitud negativa. Pero no me di por 
vencido hasta leer y releer el trabajo, guiado quizás por una débil intuición de que algo provechoso podía sacarse de esas páginas. Y, efectivamente, el rechazo que experimenté al principio se fue transformando en una especie de curiosidad no exenta de cierta simpatía: sobre todo al percatarme de que Barker, con todas sus limitaciones teórico-prácticas, tenía un profundo conocimiento de al menos ciertas características importantes de este idioma. El idioma yanomami hasta hoy nos ofrece sorpresas y nos sigue desconcertando con una fabulosa riqueza estructural y semántica, tal como lo demuestran -con sobrantes argumentos y elementos- la lingüísta franco-venezolana Marie-Claude Mattei-Müller, con su admirable Diccionario ilustrado "Lengua y cultura yanomami" (MatteiMüller 2007) y el brillante antropólogo, también francés, Jacques Lizot en su extensa "Introducción a la lengua yanomami" (Lizot 1996). Y no son ellos los únicos autores que se han dedicado a descifrar este difícil y enigmático idioma. Estoy seguro de que ninguno de ellos reconoce a James Barker como un pionero importante en el estudio del yanomami. A mí también me iba a suceder lo mismo. Pero no; cuando recapacité tuve que recordar también que el mismo Barker inspiró y coordinó la labor de una muy importante traducción al yanomami del texto completo del Nuevo Testamento (Yai bada e täa, 1984), de la cual podemos discrepar en más de un detalle. No obstante, el "Yai bada e tẫa" la Palabra de Dios -hoy se escribiría "Yai pata e thễa- continúa siendo un aporte fundamental al conocimiento del idioma. Decidí finalmente darle luz verde a la publicación de la "gramática técnica" del misionero James Barker. Lo hice entonces en los términos siguientes que hoy, después de largas reflexiones sobre el tema, ya no comparto plenamente: mi veredicto de ahora sería mucho más positivo.

NOTAS SOBRE UNA GRAMÁTICA TÉCNICA DE LA LENGUA SHAMATARI

Es innegable el hecho de que esta gramática constituye un aporte de cierta importancia a nuestros conocimientos lingüísticos de los pueblos yanomami, los menos influidos hasta hoy por los patrones de vida occidentalizantes.

Se trata de un trabajo interesante dentro de su propio marco referencial que es la gramática tagmémica, elaborada por Pike y sus seguidores. Su enfoque aspira a una gran precisión y adecuación a los hechos, tal como el propio término "gramática técnica" lo implica. El trabajo, en su conjunto, nos deja entrever un sistema lingüístico de gran complejidad, claramente diferente de las demás lenguas indígenas del país.

¿Por qué decimos entrever nada más? Lamentablemente, el procedimiento de los casilleros tagmémicos es demasiado apretado y escueto. La ejemplificación es insuficiente y haría mucha falta una traducción literal de cada morfema y posiblemente un glosario. 
Aun así, pese a ciertas inconsecuencias en la transcripción (uso de k, c y qu para un solo fonema), este trabajo es meritorio y refleja un gran esfuerzo analítico, además del conocimiento del yanomami (aunque no siempre del castellano). Esteban Emilio Mosonyi (apud Barker 1979)

Hoy, veinticuatro años más tarde, ya no diría que este estudio tan solo deja entrever algunas de las características del idioma yanomami. Sin desconocer sus grandes limitaciones, esta minúscula gramática de apenas treinta y seis (36) páginas explica una cantidad de hechos, si no de un modo satisfactorio, por lo menos con una aproximación digna de respeto, ante el desafío que al autor le tocaba enfrentar. Tampoco es tan cierto que esta descripción lingüística obedece a los cánones de la metodología tagménica de Pike, si bien está fuertemente influida por ella. Barker no trata de llenar casillas creadas para contener realizaciones de funciones gramaticales. Él más bien establece un largo y complicado encadenamiento de posiciones sucesivas, que se convertirán a su vez en receptoras de conjuntos de morfemas mutuamente excluyentes, pero provistas de una heterogeneidad de funciones. Pero pasemos a examinar la obra en sí.

\section{III.}

Haciendo caso omiso de tantos errores y erratas, podemos dividir la presentación de Barker en varios pequeños capítulos, subdivididos internamente en secciones fácilmente reconocibles. Compartamos o no muchas de sus afirmaciones, estemos o no de acuerdo con el estilo y las ejemplificaciones, desestimando incluso la importancia de los baches debidos a palabras o frases ilegibles para el editor, será siempre justo admitir que estamos frente a un imponente retrato del idioma yanomami como estructura totalizante y en cierta forma cerrada. Además tiene la pretensión, más o menos lograda, de aspirar a un alto grado de precisión y credibilidad, al desechar todo lo accesorio y aparentemente superfluo.

El primer capítulo, algo más de seis páginas, está dedicado a la fonología, de la cual logra una aceptable síntesis. Muy al comienzo, Barker hace unos señalamientos generales en cuanto a la ubicación del dialecto del yanomami denominado por él shamatari, cuyo topolecto kalina ("calina" según su transcripción) será objeto de su descripción, tal como se habla en la comunidad de Pishaasitheri ( sitio del pimpollo del platanillo), en la orilla del Orinoco cerca de la desembocadura del río Mavaca. Según el autor, los demás dialectos o variantes mayores del idioma serían el sanemá (sanimá), el ninam y el yanomami (yanomami) central. Pero resulta que mientras los dos primeros llegan a constituir idiomas distintos apenas intercomprensibles con el resto, el shamatari 
(más exactamente shamathari, con la " $t$ " bien aspirada) y el yanomami central llamado por Barker "waika central"- presentan solamente divergencias menores y su comprensibilidad mutua es excelente.

Volviendo a lo propiamente fonológico, Barker presenta correctamente 19 fonemas, 7 de los cuales son vocales y el resto -un total de 12, número relativamente bajo- consonantes, que no admiten discriminación entre sordas y sonoras. Las vocales -son prácticamente las mismas del castellano, con la adición de la /a/ central (transcrita "ä" por el autor, pero hoy con claro predominio de la grafía ë), y de la /ì central (transcrita "ö" por Barker y actualmente representada por “ “””). Solo en atención a los lectores menos versados en lingüística, aclaramos que se trata -con algún grado de aproximación- de los sonidos de las dos primeras vocales de la palabra inglesa "service", respectivamente.

Hénos aquí el alfabeto completo del idioma yanomami, transcrito según las grafías de Barker (lado izquierdo) y mediante el alfabeto hoy en uso preferencial (lado derecho).

$\begin{array}{ll}\text { a } & \text { a } \\ \ddot{a} & \text { e } \\ \text { d } & \text { t } \\ \text { e } & \text { e } \\ \text { i } & \text { i } \\ \text { j } & \text { h } \\ \text { k (c, qu) } & \text { k } \\ \text { m } & \text { m } \\ \text { n } & \text { n } \\ \text { o } & \text { o } \\ \ddot{o} & \text { i } \\ \text { p (b) } & \text { p } \\ \text { r }(1) & \text { r } \\ \text { sh } & \text { sh } \\ \text { t } & \text { th } \\ \text { u } & \text { u } \\ \text { w } & \text { w } \\ y & y\end{array}$

Ya insinuamos que la /p/, la /t/ y la /k/ (según la transcripción actualizada) pueden ser sordas o semisonoras, es decir cercanas a /b/,/d/,/g/. La /r/ oscila 
entre "ere" simple, "ele-ere" y "ele" normal según las investigaciones más confiables. Tanto la "j" de Barker como la "h" del alfabeto actualizado suenan como "h" aspirada, similar a la de "hat" ("sombrero" en inglés). Aparte de eso, no creo que haya necesidad de discutir más extensamente algunos de los matices fonéticos descritos por Barker, ya que los mismos no afectan para nada al sistema fonémico como tal. Es igualmente correcta su constatación de que el acento de intensidad tampoco tiene carácter fonémico. El "capítulo" sobre fonología culmina con unas notas sobre entonación y ritmo, que en su conjunto son bastante aceptables. Aquí los reproducimos sin más comentarios; dejando intacta la transcripción original y corrigiendo tan solo algunas erratas y errores evidentes.

\section{El Acento en la Prosa}

La frase fonética consiste de una palabra más todas las palabras monovocálicas que la siguen dentro de la misma frase gramatical.

En la frase fonética el acento cae sobre:

(1) la primera vocal.

(2) la penúltima vocal.

(3) cada non (es decir, "cifre no-par". Nota del Autor del artículo) vocal excepto la última.

$[\ldots]$

En la prosa el acento no es fonémico y no se marca. Aquí hemos marcado unos ejemplos solamente para ilustrar la regla:

$\begin{array}{llll}\mathrm{mó} & (\text { semilla }) & \text { áúshi } & \text { (blanco) } \\ \mathrm{u} & (\text { río }) & \text { pújíi } & \text { (querer) } \\ \mathrm{ka} & (\text { hueco }) & \text { jí́ma } & \text { (perro) } \\ \text { ái } & (\text { alguno }) & \text { kárädímö } & \text { (culebra coral) } \\ \text { júu } & (\text { andar }) & \text { áyakórámö } & \text { (un pajarito) } \\ \text { yúri } & \text { (pez) } & \text { yórowájirímö } & \text { (cachicamo) } \\ \text { ára } & \text { (guacamayo) } & \text { jáyakówaríyóma } & \text { (espíritu silvestre) } \\ \text { kúráta } & \text { (plátano) } & \text { Bísaásitériyóma } & \text { (mujer de Bisaasi) }\end{array}$

Una palabra monovocálica cambia el acento que la palabra anterior hubiera tenido si quedaba al fin de la frase fonética. Hay que siempre recordar que el acento no cae según la palabra pero según la frase fonética.

Ya yáji táma.

Yá yáji rä táno wéi.
(Hice la casa).

(La casa que hice). 
Yá kúráta pújíi.

Yá kúráta pä rä pújíno wei.

Péi ká ya yó ka.

Kúráta, á wáréma.
(Quiero el plátano).

(Los plátanos que yo quería).

(Es mi camino).

(Comió un plátano).

Una frase fonética nueva empieza con cada palabra polivocálica y con cada frase gramatical nueva.

\section{El acento en los Cantos}

En los cantos el ritmo del canto reemplaza el ritmo normal de la prosa. Cada canto tiene su propio ritmo. Por eso hay que decir que el acento en los cantos es fonémico y marcarlo con el acento agudo.

Shóriwä, ípa nojí.

Sípara kä, yá pä bují́.

Wáre da dó, dópäshó.

Kámiyä yá, shí öjödé.

Shóriwä kä, yámakö jorí.

Yá pä no kó, kówamaö wä.
(Cuñado, mi amigo).

(Quiero un machete).

(Enriquézcame usted).

(Yo mismo, soy generoso).

(Cuñado, nos hace falta).

(Yo voy a pagarles)

[...] (Barker 1979:199)

El detalle que más se presta a discusión es la interpretación por Barker de la nasalidad fonémica de las vocales como extensiva al lexema completo, lo que ha sido parcialmente rebatido por Mattei-Muller y más radicalmente por Lizot. Con todo y eso, llama mucho la atención lo completo y ordenado de la sección fonológica, a pesar de su brevedad esquemática. También describe algunos sonidos extrafonémicos como son ciertos chasquidos usados con valor exclamativo.

Lo que podríamos llamar el capítulo segundo abarca aproximadamente 16 páginas y es considerablemente más complejo; sin embargo, no deja de tener cierta transparencia muy ventajosa para su interpretación unívoca. Se refiere en su totalidad a las diferentes clases de palabras que existen en el idioma. Para Barker serían las seis siguientes: sustantivos, pronombres, verbos, adverbios, posposiciones, prefínales. Los sustantivos aparecen divididos en a) los de posesión obligatoria, b) los de posesión optativa y c) las partes del cuerpo. La descripción que hace Barker de estas tres subclases es somera, pero bastante acertada y convincente dentro de los límites propuestos. Los pronombres están descritos y explicados de manera muy sencilla y pedagógica, siendo esta una de las secciones más logradas de esta síntesis gramatical. Y aquí vale la pena destacar que un elogio de esta naturaleza es muy significativo, en vista de la gran complejidad estructural del prolijo inventario de pronombres personales en este idioma con características ergativas: entre estas se destaca la obligatoriedad 
- con algunas excepciones - de la partícula -ní para indicar el sujeto activo de la oración. Ej: ira-ni a hiima warema (tigre-ergativo el perro comió); el tigre se comió al perro. La misma particula también posee valor instrumental: pasho pëni pei shina-ni hii hi pë humëwaihe (mono el-ergativo cuerpo cola-ergativo árbol rama plural se-agarra), el mono se agarra de las ramas por la cola. Posiblemente lo menos aceptable en su descripción sea el haber denominado al pronombre "thë" tercera persona honorífica, aunque en ciertos contextos dicha interpretación sea defendible. En nuestro criterio "thë" es fundamentalmente un pronombre anafórico de tercera persona, que también se usa como tercera persona generalizada con significado aproximado de "uno"; de allí se desprende su ocasional uso honorifico, para algo o alguien percibido como un ser espercial o que no necesita nombrarse explícitamente.

\section{$[\ldots]$}

Los Pronombres

En los pronombres se distinguen tres números:

(1) el singular

(2) el dual

(3) el plural de tres o más personas

No hay género en los pronombres. No se marca número en los sustantivos. Por el pronombre que lo representa se sabe el número de un sustantivo.

Los pronombres interiores son obligatorios. Los pronombres exteriores son optativos. Los sustantivos son optativos.

Los pronombres interiores

Hay dos grupos de pronombres interiores. Los verbos intransitivos utilizan un grupo, y los verbos transitivos otro.

Los que se encuentran con los verbos intransitivos son:

$\begin{array}{lcll} & \text { singular } & \text { dual } & \text { plural } \\ \text { Primera persona exclusiva } & \text { ya } & \text { yajäkö } & \text { yamakö } \\ \text { Primera persona inclusiva } & & \text { päjäkö } & \text { pämakö } \\ \text { Segunda persona } & \text { wa } & \text { wajäkö } & \text { wamakö } \\ \text { Tercera persona ordinaria } & \text { a } & \text { käköpö } & \text { pä } \\ \text { Tercera persona honorífica } & \text { tä } & \text { täköpö } & \text { täpä }\end{array}$

No hay artículos definidos ni indefinidos. La idea se representa por el orden en que se encuentran los sustantivos y los pronombres.

Mididi ja, öra $a$ juu.

Mididi ja, $a$ öra juu.

Mididi ja, $a$ juu.
(Un tigre anda de noche).

(El tigre anda de noche).

(El anda de noche). 
Ora jamö, ya juu.

Koro jamö wa mö wärörayojäröma.
(Yo andaba río arriba).

(Usted bajaba de aquí por río).

Los pronombres intransitivos se encuentran también en frases que no contienen verbos.

Mono teriyoma kä ya.

Jawari kä $a$ koko.

Yuri yokarewä kä wa.

Pei kä wa mamikö.
(Soy mujer del pueblo de la lengua).

(Es nuez de yuvía).

(Eres pescador).

(Tus pies).

Un verbo transitivo lleva dos pronombres - un sujeto y un complemento. Cuando el sujeto es de la primera ó la segunda persona y el complemento es la tercera persona, los pronombres interiores son:

$$
\text { sujeto }
$$

Primera persona exclusiva

Primera persona inclusiva

Segunda persona complementos

Tercera persona ordinaria

Tercera persona honorífica

singular
ya
wa

$\begin{array}{lll}\mathrm{a}_{1} & \text { käkö } & \text { pä } \\ \text { tä } & \text { täköpö } & \text { täpä }\end{array}$

1) Los sujetos ya y wa suprimen el complemento a.

Ya pujii. (Yo lo quiero). Wa warema. (Tú lo comiste).

Todas las combinaciones de los sujetos y complementos arriba son posibles, y en todas el sujeto precede al complemento.

Kurata ya pä pujii.

Sipara yama köpö nakama.

Yuri päjä pä yokarema.

Öra ya tä mo kirii taö.

Wa pä pujii.
(Quiero plátano).

(Pedimos los dos machetes).

(Usted y yo sacamos unos pescados).

(Tengo miedo de un tigre).

(Usted los quiere)

\section{[...] (Barker 1979:202)}

El tratamiento de los adjetivos y adverbios que hace Barker es mucho más complicado y a veces poco transparente, pero aun con esas reservas no deja de encajar en el conjunto sistémico ideado por el autor. El problema de los adverbios se le vuelve especialmente espinoso en vista de la heterogeneidad de esta categoría y de los múltiples cambios alomórficos que su presencia puede implicar: algo que merecía ante todo una ejemplificación bastante más completa, para poder ser asimilado por el lector con cierta formación lingüística. 
Barker comienza el tratamiento de los verbos en este mismo segundo capítulo, donde los caracteriza principalmente en términos de un número muy preciso, concretamente de seis grupos diferenciados en lo formal y lo semántico.

El tercer capítulo está dedicado casi íntegramente a los llamados sufijos verbales. Barker denomina las seis clases principales de verbos en la forma siguiente: a) los adjetivos (que Barker considera verbos por una serie de coincidencias fundamentales con esa categoría), b) los verbos de actividades, c) los verbos de posiciones, d) los verbos de complementos afectados, e) los verbos de complementos obtenidos, f) los verbos de complementos a posiciones. En el peculiar español de Barker los complementos obtenidos - no tan solo afectadosson los que de alguna manera entran en al ámbito del sujeto, tales como "escuchar", "comprar", "recoger". Mientras tanto, los verbos de "complementos a posiciones" son simples causativos como "hacer dormir", "dejar caer". El análisis aparece límpido, muy profesional, ajeno a todo tipo de especulación o divagación arbitraria. Se evidencia que cada una de esas clases obedece a características tanto formales como semánticas bien marcadas, incluyendo sus alomorfos fonológicamente determinados. Por ejemplo, la segunda clase de verbos se caracteriza por el hecho de que su forma básica -no precisamente la raíz sino una especie de infinitivo- tiene como marca una de las vocales altas $/ \mathrm{i} /, / \mathrm{i} /, / \mathrm{u} /$, según sea el punto de articulación de la vocal anterior. En cuanto a la semántica de las distintas clases de verbos, se revela la fineza clasificatoria del idioma yanomami, que haría las delicias de autores como Whorf, Sapir o quienquiera siguiese sus orientaciones fundamentales, que focalizan las interrelaciones entre lengua y cultura. Ofrecemos como ejemplo la exquisita diferenciación que se observa-semántica y formalmente- entre las clases cuatro (4) -complementos afectados- y cinco (5) -complementos obtenidos-. En ese sentido, verbos como shaii (halar, arrastrar), tomii (robar), solo movilizan o perturban el objeto complementario, sin necesariamente modificar su relación con el sujeto; mientras tanto, otros verbos como hirii (escuchar), rurai (comprar), sí implican que el objeto se pasa al ámbito personal del sujeto activo.

Pasando ya al tercer capítulo, nos encontramos con el planteamiento quizás más original y osado de nuestro autor. Allí Barker establece la continuidad lineal de nada menos que veinte posiciones secuenciales, vale decir, un radical verbal y 19 sufijos. Lo de sufijos debemos tomarlo con un granito de sal, ya que varias de estas formas tienden a aparecer más bien aisladas. En efecto, el yanomami como lengua tiende tipológicamente a la categoría de lengua semi-aislante, en lo que discrepa de la mayoría de las familias vecinas, claramente identificables como sintéticas, a veces hasta polisintéticas.

Pero volvamos a las veinte posiciones, cada una de las cuales contiene o al menos debería incluir un conjunto de morfemas mutuamente excluyentes. Tanto por su coherencia interna como por nuestra experiencia con esta y otras lenguas amerindias, estamos en condiciones de asegurar que Barker logra aquí 
también una buena síntesis inicial, abierta naturalmente a ulteriores adiciones y rectificaciones como por fortuna viene acaeciendo. Por ejemplo, Barker no toma en cuenta -quizás ni siquiera se plantea su existencia- las decenas de morfemas clasificatorios tan bien descritos por Lizot. En ese mismo sentido no parece percatarse, por lo menos en el presente trabajo, de la real importancia estructural de la composición e incluso derivación nominal y verbal. Tampoco experimentaba la sensitividad de Marie-Claude Mattei-Muller frente a la sólida arquitectura del sistema de sufijos verbales que expresan tres distancias deícticas, a saber, próxima, intermedia y remota. Podríamos así multiplicar las fallas; nada más fácil para el crítico que jamás asistió a los dolores del parto, pero veamos ahora los éxitos obtenidos.

Sin ser exhaustivos ni mucho menos, en estos veinte órdenes observamos análisis bastante claros, concisos y cuando menos parcialmente logrados como los siguientes: una satisfactoria delimitación entre los aspectos puntual y progresivo; una acertada sistematización de las voces en activa, pasiva, reflexiva y recíproca (mii, ver; mimou, ser visto; miu, verse a sí mismo; miyo, verse recíprocamente); la precisa delimitación de los números dual y plural (-pi, -he); la importante diferencia estructural entre los órdenes inferiores y superiores de sufijos; la ubicación del causativo "mą"; la estrecha relación entre las clases de verbos y sus particularidades aspectuales y modales, incluidos los alomorfos; la forma y posición de los sufijos de negación; varias características fundamentales de la relativización en -rë y otras formas de subordinación sintáctica.

Con todas las fallas y carencias ya más o menos enumeradas, podemos asegurar sin embargo que el conjunto de la presentación que hace Barker de la gramática yanomami en sus lineamientos generales expone a nuestra vista algo caracterizable como una majestuosa catedral barroca, construida a base de filigranas verbales convergentes en un todo armonioso de seductora complejidad conceptual y formal, unida a una muy original perfección estética, difícilmente comparable -aun cuando no superior ni inferior- a las demás lenguas del mundo, inclusive las vecinas. Si la única creación del pueblo yanomami hubiese sido su hermoso idioma, ya con ello merecería todo nuestro respeto y admiración.

\section{IV.}

Antes de proceder a nuestras palabras finales, vamos a presentar como prueba de la capacidad analítica de James Barker otra más de las páginas constitutivas de su importante síntesis gramatical, haciéndole unas correcciones mínimas en lo tocante a las erratas y errores más gruesos. De nuevo respetaremos la transcripción utilizada por el autor. 
$[\ldots]$

La posición posterior

No es raro tener hasta tres adverbios entre los sufijos del verbo a la vez. Los adverbios siguen al orden número cinco de los sufijos verbales y los sufijos de órdenes superiores se adhieren al adverbio último en vez del verbo.

A jokäa jenaa korayojäröma.

(Se fue otra vez de mañana).

A juu moji je parojowä.

(No tiene ninguna ganas de ir).

Pä ishou jaöo koo maikätä.

(No volverán a pelear pronto).

Pä juu jaöo shi dobrao koo weikätä. $\quad$ (Tendrán ganas de volver pronto).

Los Adverbios de grado

Estos adverbios modifican adjetivos ú otros adverbios.

paröwä (más)

nojao (menos)

piyäwä (un poco menos)

dodijiwä (verdaderamente)

je parojowä (muy)

La comparación de adjetivos muchas veces toma una forma paralela que requiere dos cláusulas.

Jei cä a bada paröwä, miji cä pada nojao.

(Este es más grande, ése es menos grande).

Jei cä a pada, miji cä a waisipö.

(Este es grande, ese es pequeño).

Äjä a pada paröwä marä kuwi, ipa a marä wisipi.

(Es evidente que tu tienes el más grande, el mío se ve que es muy pequeño).

El grado absoluto requiere una sola cláusula.

Ipa a riyäjä wä dodijiwä.

(El mío es verdaderamente bonito).

A suwäjärö riyäjä wä je parojowä.

(La niña es muy linda).

Tä mididi je parojowä däjä, a öra juu.

(El tigre viene cuando está muy oscuro).

Pada u karäö ropä̈ je parojowä.

(El río grande corre muchísimo)

[...] (Barker 1979, pág 203) 
Ya para ir cerrando quiero manifestar que estoy perfectamente consciente del alto grado de excelencia y originalidad prístina del inmortal gramático hindú Pánini, el primer gran maestro de la sacratísima lengua sánscrita, prototipo indiscutible de la hoy todavía dominante familia indoeuropea. Aun así no me arrepiento de haber llamado a Barker, un tanto metonímicamente, el Pánini de la lengua yanomami. Creo haber demostrado este aserto en las páginas anteriores. Pero resta todavía responder a una pregunta que seguramente muchos de los lectores ya se habrán formulado. ¿Funciona realmente esta síntesis gramatical como código para descifrar diferentes tipos de textos yanomami o, al revés, construir textos o expresiones, bien sea de naturaleza coloquial o de otra índole? La respuesta ha de ser un sí rotundo por una multiplicidad de razones. Primero que nada, las Misiones Nuevas Tribus -gústenos o no- han emitido una multitud de folletos y otras breves publicaciones, destinados a la evangelización y a la educación elemental, y como tales han funcionado.

Pero mucho más allá de dichos intentos parciales, si se quiere incipientes, está la verdaderamente monumental traducción del Nuevo Testamento, que ni siquiera con los más extremos prejuicios puede ser menospreciado; tal vez sí criticado en algunas de sus características. Todavía falta por hacer un estudio crítico sistemático de esta Biblia yanomami; especialmente ahora cuando la Educación Intercultural Bilingüe y Plurilingüe entra en una etapa de madurez que requiere la elaboración de textos no siempre ni necesariamente vinculados a las culturas indígenas (Caballero, 2011). También sería interesante una segunda edición crítica corregida y mejorada de esta misma gramática pionera del misionero norteamericano.

Falta todavía por agregar algo de mi propia experiencia personal con el idioma yanomami. Hace ya no sé cuántos años, cuando hacía mis primeras armas en este rico idioma, me tocó enfrentar una vivencia muy curiosa, para mí inolvidable. En esa época, por razones académicas y profesionales, se me hacía necesario viajar con cierta frecuencia al Amazonas venezolano y eso implicaba también otros tipos de contactos y compromisos. En una oportunidad, un señor criollo que realizaba un trabajo -no recuerdo los pormenores- en distintas zonas del Alto Orinoco se presentó en mi oficina con el siguiente discurso. Decía que con él andaba a la sazón un hombre joven adulto, de la etnia yanomami, casi monolingüe en su idioma, acompañado de un hijito suyo que necesitaba ser operado en el Hospital Universitario de Caracas. Repito que ya casi no me acuerdo de los detalles del caso; lo que sí sé es que el señor yanomami no estaba muy convencido de lo necesario de esa intervención quirúrgica, aunque tenía toda la voluntad de salvar a su muchachito. Ante esa coyuntura, el amigo criollo se dirigió a mi persona pidiéndome ayuda, esta vez de naturaleza lingüística. Él presumía que yo sabía yanomami, si bien en realidad apenas me estaba iniciando en el mismo y bajo la modalidad de puro estudio autodidáctico. 
Uno de mis materiales disponibles para ese momento era el breve texto de Barker, y junto a él una suerte de diccionario bilingüe, de origen también misional. Yo estaba verdaderamente preocupado, pero no quise negarme a esa petición, de la cual dependía probablemente la vida de un niño. Por eso le dije que sí al criollo, y el mismo día me encerré en mi casa para redactar un breve pero inteligible texto en idioma yanomami. Estaría destinado a convencer al padre del niño de la necesidad de la operación, y al mismo tiempo tranquilizarlo de que su hijo pequeño no corría ningún riesgo, por tratarse de un acto quirúrgico breve y rutinario. Más fácilmente de lo que había pensado, obtuve mi propósito; tal vez debido a mi estado de motivación y al interés por salvar al niño. A mi modo de ver el texto yanomami quedó incluso bastante bonito, además de hecho con amor y los mejores propósitos.

Al día siguiente, temprano en la mañana, aparecieron en mi casa los dos señores, el criollo y el yanomami. Como ya dije, este era una persona muy poco aculturada y trataba de administrar de la mejor manera posible las poquitas palabras en castellano que sabía utilizar. Andaba vestido de blanco, su ropa era limpia e impecable y se desenvolvía con una cortesía admirable y unos modales exquisitos. Incluso mi madre, que tenía poca experiencia con indígenas, se quedó impresionada con esa conducta suya tan señorial. Entonces yo leí mi texto en yanomami muy lentamente y con el mayor cuidado. ¿Entendiste todo lo que te leí? le pregunté al hombre yanomami, que estaba sumamente pendiente de mis palabras. A lo que este contestó. "Sí, entiendo todo. Tú tienes hékura" (espíritu bueno). Me quedé muy impresionado y agradecido por esa respuesta tan elogiosa. Después supe que el niño había sido intervenido con éxito. Logró ser salvado.

Al cabo de tantos años solo quiero agregar: no cabe duda de que también sobre Barker actuó el influjo de un hékura al redactar su gramática. Su aparente tosquedad revela una buena dosis de inspiración científica y artística.

\section{Bibliografía consultada}

Barker, James. 1979. Una gramática técnica de la lengua Shamatari (notas por Estaban Emilio Mosonyi). Boletín Indigenista Venezolano: Tomo XVIII, XVIII (15): 193 226.

Caballero Arias, Hortensia. Los yanomami. Caracas: Fundación el perro y la rana, 2011.

Escobar, Ticio. Misión: etnocidio. Asunción (Paraguay): Comisión de solidaridad con los pueblos indígenas, 1988.

Lizot, Jacques. Introducción a la lengua yanomami. Caracas: Vicariato Apostólico de Puerto Ayacucho- Unicef, 1996.

Makkai, Ádám. Bábel Tornyától a szentlélek kitöltetéséig (Desde la Torre de Babel hasta el descenso del espíritu santo). Új látóhatár (nuevo horizonte). Múnich, 1984. 
Mattei Müller, Marie-Claude. Lengua y cultura yanomami. Caracas: Épsilon libros, 2007.

Pike, Kenneth L. Language in relation to a unified theory of the structure of human behaviour. Glendale, California: Summer Institute of Linguistics, 1954.

Yai bädä e tẫa. En: Nuevo Testamento en yanomamö y castellano. Misión Nuevas Tribus de Venezuela, 1984.

Data recebimento: 05/11/2014.

Data aceite: 20/11/2014. 